\title{
Inclusion in STEM: Challenges for Education in Engineering
}

\author{
https://doi.org/10.3991/ijep.v10i6.19681 \\ Carina Soledad González-González \\ University of La Laguna, Tenerife, Spain \\ carina.gonzalez@ull.edu.es
}

It is a great pleasure to contribute some words to the discussion on Engineering Education and add some topics such as inclusion, diversity, and equity as challenges that the area is facing. Also, thanks to the International Journal of Engineering Pedagogy (iJEP) and its editor-in-chief, Matthias Utesch, as well as to the collaboration between the IGIP (International Society for Engineering Pedagogy), IAOE (International Association of Online Engineering), and the IEEE (Institute of Electrical and Electronics Engineers), in particular, to the IEEE Education Society for their contributions to the education in the Engineering discipline.

I will start on the discussion of the previous editorial "Relationships Among Economy, Industry, Vocational Education and Training and Higher Engineering Education," iJEP, Vol 10, No 5 (2020) (https://online-journals.org/index.php/i-jep/article/view/ 16747). In this article, the best papers of our 9th Trefort Ágoston Conference on Vocational Education and Training and Technical Teacher Training at Óbuda University (ÓE) Electrical Engineering Faculty in Budapest, in Hungary, has been presented and discussed. Several challenges and strategies related to the Fourth Industrial Revolution, Higher Education, and industries have been analyzed. In this sense, I agree with the identified needs for the Engineering Higher Education and industry, like the following:

- Very competent students with robust aptitudes of Maths and essential STEM areas.

- Dedicated pupils with good knowledge about the selected profession and their needs.

- High-level of STEM education with an equilibrium of theoretical fundaments and practice.

- Appropriate knowledge of the Labour Market supported by industry instruction and training.

- A request for a foreign language with good skills in its use.

- Reduction of the rate of dropout in the early years of the career.

Moreover, this editorial identifies as a key to entry to engineering education at secondary schools' vocational STEM activities. I want to add to this discussion for the challenges of education in engineering and industry: the lack of women in STEM careers, which is mainly a vocational related issue, which starts at early ages.

Currently, there is a huge problem in society and the work market relating to digital competencies and the gender gap. Forthcoming works require digital competencies, and there are even diminished segments of the population, as women, in technical jobs, and engineering studies. 
Although several actions have emerged to increase women's presence in technological careers, the imbalance is still very high. Diversity and inclusion must be encouraged in educational settings from childhood. If women feel excluded from STEM careers and jobs, the gender gap will continue to grow. A non-inclusive society loses the talent of its people. Therefore, different solutions are needed to reduce the gender gap, such as providing inclusive educational and work environments.

Various studies have shown that the probability of women choosing technological, engineering, or science careers, therefore graduating and entering the professional sector is very low. The factors that influence the gender gap in the technological area are diverse, ranging from lower pay at work to perceptions of gender stereotypes.

Also, women's self-perception of lower effectiveness in STEM issues negatively influences career choices and scientific vocations. There is also a higher dropout among women in STEM careers, resulting in fewer women in the workforce. There is also a lack of female role models in technology-related jobs.

Besides, the barriers to be overcome may be conscious or unconscious. These barriers are related to biases that can distort reality and also to artificial intelligence algorithms and data. For example, in Spain, in the area of artificial intelligence, more than $80 \%$ of its researchers are men. If we think about a future of intelligent cities, sensorized, managed by robots and algorithms, we see that it is urgent to incorporate women in technological careers.

There is also a lack of knowledge about STEM and the professional development of these careers. Therefore, we must provide models and publicize the various professional outputs of STEM careers from engineering education.

It is essential to have diversity in the workforce since the difference promotes talent, innovation, and inclusion of the entire social spectrum.

Therefore, one of UNESCO's Sustainable Development Goals (SDG) promotes gender equality and women's empowerment throughout society, including in the labor market. Gender equality can be seen as a cross-cutting objective present in several sustainable development goals, such as ensuring equitable and inclusive quality education and promoting lifelong learning for all. The SDGs also seek sustainable and inclusive economic growth that takes into account the situation of women.

In this sense, universities have a crucial role in promoting SDGs, and in the case of STEM careers, we clearly see a challenge to be faced, particularly with the gender gap and the knowledge and skills needed by the digital society. Therefore, these issues should be a key objective of universities and engineering schools and should be introduced in the teaching and learning processes.

During several editions of the IEEE Global Engineering Education Conference (EDUCON) we have organized different activities to analyze the gender gap in STEM education and the industry, promoting inclusion and diversity in Engineering. For example, we have organized several round tables about "Women in Engineering," analyzing the gender gap, unconscious bias, STEM, and diversity, among other challenges. Also, we have organized round tables with women from industry, like Microsoft, IBM, or Google, to analyze the actions for encouraging women in technology from the companies' point of view. We also have proposed educational methods and strategies to incorporate equity and diversity in Engineering studies. Thus, there are several 
challenges to face for the education in Engineering related to inclusion in STEM. The next edition, Austria organized by the Carinthia University of Applied Sciences and the University of Applied Sciences Technikum Vienna, Austria, will be focused on "Women in Engineering" as the main topic. Thus, this topic a challenge for the academics that work on Engineering Education and are looking for a more inclusive society.

Carina S. González

La Laguna, Tenerife, Spain, November 2020

Carina S. González is a Full Professor of Computer Architecture Technology at the Department of Computer Engineering and Systems of the University of La Laguna (Spain). Carina is a Ph.D. in Computer Science (2001) from the University of La Laguna and a Ph.D. in Social Science and Education (2020) from the University of Huelva (Spain). Bachelor in Computer Science (1995) by the National University of Northeast (Argentina), certified as Computer Engineering by the Spanish Ministry of Education (1999). She is also certified in "Early Childhood Technology" by Tufts University (USA). She is the head of the research group Interaction, ICT, and Education (ITED). Carina is Chair of the Digital Culture of the University of La Laguna. She has been Director of the Innovation and Educational Technology (2011; 2015-2019). For more than 20 years, her research has focused on the field of Informatics applied to Education and Human-Computer Interaction (Intelligent Tutorial Systems, Adaptive and Customizable Interfaces, Educational Video Games, Gamification in Education, e-learning, digital culture), participating in different research projects and publishing widely on these topics. She was co-chair of the conference IEEE EDUCON 2018 (Engineering Education Conference) organized by the IEEE Education Society, among other international conferences. She is an Associate Editor of the IEEE Transactions on Education and edited several special issues of IEEE-RITA (Revista Iberoamericana de Tecnologías del Aprendizaje) of the Spanish Chapter of the IEEE Education Society. Also, she is a Senior member of IEEE. 